\title{
Crônica e cotidianidade
}

\section{Chronicle and day-to-day life}

\author{
GILDA VILELA BRANDÃO \\ Universidade Federal de Alagoas - Maceió - Alagoas - Brasil
}

\begin{abstract}
Resumo: Gênero textual volátil, a crônica tem, como matéria-prima, o factual. Como critério primordial de análise, o presente artigo prioriza a categoria da cotidianidade. O recorte analítico privilegia os relatos dos viajantes estrangeiros (Henry Koster e Henri Coudreau) e a crônica de João do Rio. Ainda que de forma incompleta, examina-se também a crônica de Machado de Assis.
\end{abstract}

Palavras-chave: Crônica; Cotidianidade; João do Rio; Machado de Assis

\begin{abstract}
A volatile textual gender, the chronicle has, as its raw material, the factual. As a primordial criterion of analysis, this article emphasizes the category of the day-to-day. The analytical observation underlines the reports of the foreign voyagers (Henry Koster and Henri Coudreau) and Joao do Rio's chronicle. Although in an incomplete way, Machado de Assis' chronicles are also examined.
\end{abstract}

Keywords: chronicle; day-to-day life; João do Rio; Machado de Assis

\author{
No Brasil, ela [a crônica] tem uma \\ boa história, e até se poderia \\ dizer que sob vários aspectos \\ é um gênero brasileiro.
}

(CANDIDO, 1992, p. 11)

Narrativa dos feitos heroicos de reis e condestáveis, a crônica medieval nasce intramuros, nos espaços do poder monárquico. Limitada ao ambiente restrito da corte, a crônica (do étimo chronos) guarda, pois, em seus primórdios, um caráter aristocrático de que é exemplo a Crônica do Condestável de Portugal, escrita por um autor anônimo do século XIV:

Estando assim o Prior e com ele Nun'Álvares na frontaria de Lisboa, el-Rei de Castela, filho de El-Rei D. Henrique, que já era morto, juntou suas gentes e foi-se a Badajoz a por batalha ao rei de Portugal. E D. Fernando aprestou igualmente as suas gentes e [...] se foi a Elvas. Os reis e seus exércitos estavam frente a frente (p. 51-52).

No século XVI, com a descoberta do novo mundo, essa tradição narrativa de contar fatos e histórias não fenece. Absorvida pelo relato de viagem - "gênero deglutidor de gêneros [que] pode incluir tanto o diário de bordo quanto o tratado científico [...], sem esquecer as cartas (reais ou inventadas), as anedotas em forma de contos [...]”, (ETTE, 2004, p. 10) -, a crônica alcança espaços geográficos até então desconhecidos, difundindo, mundo afora, mitos como o do estado de inocência (locus amoenus) - topos por excelência das narrativas fantásticas seiscentistas europeias.

Escritos por viajantes-escritores (voyageursécrivains), e não por escritores-viajantes (écrivainsvoyageurs) (GOULEMOT, 2004, p. 22), relatos de viagem são, de per se, crônicas, isto é, textos informativos, narrativos e descritivos, de que é exemplo a chamada "Carta-relação", de Pero Vaz de Caminha, conhecida e divulgada, nos princípios do século XIX, pelo padre Aires do Casal, cuja linguagem é assim examinada por Mário Chamie:

\footnotetext{
A linguagem de Caminha, mesmo arrolando e consignando fatos do dia-a-dia, nunca os toma por fatos soltos, mas por situações que se contextualizam $e$ interagem entre si, gerando, nessa interação, significados [...].. A prosa, na Carta, que resulta dessa concepção narrativa é, por consequência, peregrina, pois na medida em que essa prosa avança, ela vai incorporando em si as surpresas, as variações e as novidades que ela mesma flagra e registra. (CHAMIE, 2004, p. 362)
} 
Com propósitos, claro, bem diferentes dos de Caminha, o viajante inglês Henry Koster (1793-1820) que chegou a Pernambuco em 1809, "tossindo e botando os pulmões pela boca" (BRASIL, 1976, 91) para se curar de tuberculose, relata, nos escritos reunidos em Travels Brazil (traduzido por Luís da Câmara Cascudo com o título Viagens ao Nordeste do Brasil) aspectos rotineiros relativos às suas expedições, quase sempre percorridas em ambientes inóspitos:

Era minha intenção ir até o Ceará. Solicitei um passaporte ao Governador e o obtive sem maiores dificuldades. Todos os preparativos para a jornada foram feitos e nos pusemos a caminho cerca de uma hora, ao nascer da lua, Sr. Felix, eu, John, meu criado inglês, a cavalo, armados de espadas e pistolas, e o guia negro, também montado [...] carregando um bacamarte. [...]. Durante a jornada desse dia, vimos quatro ou cinco grandes cruzes, toscamente construídas, eretas à margem da estrada. Marcam os lugares onde assassinatos foram cometidos. (KOSTER, 1978, p. 64-67)

Em viagem realizada no período compreendido entre 10 de julho e 11 de outubro de 1897, em companhia de sua mulher e de três canoeiros, Henri Coudreau (18591899) descreve as cachoeiras do Arrependido e de Itaboca e o rio Itacaiúnas. Há, no entrecho abaixo, uma evidente intenção demonstrativa, quase didática, isto é, um eixo conduzindo passo a passo a descrição e o relato. Esse eixo é a topografia, a paisagem, as atividades cotidianas; em resumo, um mundo natural onde, anonimamente, os canoeiros desempenham um papel cultural e histórico:

Uma espessa cerração branca [...] pesa sobre a Cachoeira do Arrependido [...]. Durante toda a jornada, os homens trabalham no transporte das bagagens para a casa de José da Costa. [...]. Com as caixas, com as malas, com os sacos de farinha sobre a cabeça, os homens seguem, pés descalços pela escabrosa vereda toda juncada de pedras. [...]. E se for preciso, recomeçarão amanhã, e depois de amanhã e por mais dias ainda. Bravos sujeitos, laboriosos e afáveis, com quem viajar é sempre um prazer (COUDREAU, 1980, p. 24).

Nas descrições detalhadas de Koster e de Coudreau há uma trilha que ainda constitui o eixo discursivo da crônica moderna: o registo factual, o cotidiano, o diaa-dia. Nesse sentido, os exploradores e os viajantes estrangeiros, que por aqui aportaram em tempos coloniais, foram os primeiros que, lançando sobre o diferente um olhar de diversos matizes - esquivo, afável, curioso, altivo, compassivo, presunçoso - fundaram um método de abordagem do mundo empírico baseado na observação, de que é exemplo, ainda, a citação a seguir:
Quando [eu] pensava na completa mudança de hábitos que esse gênero de vida exigia e como eram diversos dos vividos na Inglaterra [...] ; quando olhando em torno de mim, via as várias fogueiras [...]; as malas e mais partes da bagagem espalhada [...]; quando notava estar no seio de um povo cujos hábitos pouco conhecia. [...] caía numa depressão moral [...]. Era reanimado pela idéia de saber o idioma do país e pela resolução de, conforme os costumes do povo, a eles submeter-me fielmente. (KOSTER, 1978, p. 81-82).

A curiosidade etnográfica, a coloquialidade, o tom pessoal (quase resvalando para a intimidade) encobrem uma camada movediça, escorregadia, sobre a qual circulavam viajantes como Koster e Coudreau: a cotidianidade, "mundo fenomênico em que a realidade se manifesta de um certo modo e ao mesmo tempo se esconde" (Kosik 1979, p. 72). Entendida como modo de organização das estruturas sociais e políticas de uma determinada época, condicionada às ideologias e aos hábitos culturais, a cotidianidade interfere na convivência social e política dos indivíduos: "A cotidianidade não significa a vida privada em oposição à vida pública. Não é também a chamada vida profana em oposição ao mais nobre mundo oficial: na cotidianidade vive tanto o escriturário quanto o imperador" (KOSIK, 1979, p. 69. Grifo de Kosik).

Lefevbre (1972, p. 88) esclarece esse intrincado conceito:

Donde sorprender la cotidianidad? Contestaremos esta pregunta de manera también aparentemente ambígua: La sorprendemos en todas partes y en niguna. No consiste ni en la vida familiar con su entorno y relaciones, ni en las distracciones, el ocio y sus actividades múltiples. Y, al mismo tiempo, es todo esto, la vida del ser humano que va de lo uno a lo otro, que se realiza y pierde tanto en el trabajo como en la família o el ocio.

Nada mais indefinido do que o cotidiano. Mas é exatamente neste campo rarefeito que irá se mover a crônica moderna, celeiro fértil de onde saíram, no século passado, José de Alencar, Olavo Bilac, João do Rio, Lima Barreto, Artur Azevedo e Machado de Assis.

\section{Crônica, retalhos do cotidiano}

A partir do século XIX, a impressão a vapor e a linotipo (1886) aceleram a indústria tipográfica, dando sinal de partida para a era da informação. Cético, Benjamin vê com pessimismo esta escrita do mundo moderno - o jornal: 
A escrita que no livro impresso havia encontrado um asilo onde levava sua existência autônoma é arrastada pelas ruas pelos reclames. Ela começa a erguer-se do chão. Já o jornal é lido mais a prumo que na horizontal, filme e reclames forçam a escrita a submeter-se de todo à ditatorial verticalidade. (BENJAMIN, 1993, p. 28)

O jornalismo promove o consumo, forma opiniões, divulga escândalos e crimes, como o assassinato de Gaston Calmette, em 1914, diretor do jornal "Le Figaro" pela esposa de Joseph Caillaux, ex-ministro da Fazenda. Na Inglaterra, o "The Times", fundado em 1785, ganha fama (a Inglaterra, dizia-se, era governada por "The Times") e, em 1898, o "Daily Mail", vendido a preço acessível, alcança tiragens espetaculares; nos Estados Unidos, grandes jornais, como o "New York Times" e o "New York Journal" disputam leitores. Na França, "Le Journal de Paris" (1777-1811) é considerado o primeiro periódico de formato análogo aos jornais de hoje; Théophraste Renaudot ("La Gazette") impulsiona o mercado editorial e, em 1833, Emile de Girardin funda "La Presse" (tiragem de 300000 exemplares em 1870), primeiro jornal de grande difusão, vendido a preços módicos. Ao angariar a colaboração de escritores renomados, das mais diversas inclinações literárias, a imprensa brasileira promove um novo gênero, a crônica, que, como bem afirma Arrigucci $\mathrm{Jr}$, é

lida com uma matéria muito misturada: a matéria do folhetim, pedaço de página por onde a literatura penetrou fundo no jornal, tratando dos temas mais diversos, mas com predominância dos aspectos da vida moderna. O cronista é o primeiro folhetinista, como o Alencar de "Ao correr da pena", colaborador do Correio Mercantil do Rio, em 1854 e 1855. (ARRIGUCCI, 1987, p. 56-57).

No momento em que a modernização das prensas de impressão revoluciona os países desenvolvidos, no Brasil, quase simultaneamente, "uma nova consciência do jornal [toma] corpo do ambiente" (BROCA, 1960, p. 216). Aí está o nascedouro da crônica, filha dileta do jornal, nas palavras de Antonio Candido:

[A crônica] não tem pretensões a durar uma vez que é filha do jornal e da era da máquina, onde tudo acaba tão depressa. Ela não foi feita originariamente para o livro, mas para essa publicação efêmera que se compra num dia e no dia seguinte é usada para embrulhar um par de sapatos ou forrar o chão da cozinha (CANDIDO, 1992, p. 14)..

A imprensa carioca consolida seu papel de centro difusor das ideias políticas, econômicas e literárias, abrindo espaço para a crônica de rodapé. O quanto a crônica, em seu escopo geral, não combina com o pensar lento e difícil, ficando a meio caminho entre o frívolo e o sério, foi dito sabiamente por Machado de Assis, quando utiliza, para defini-la, a imagem-síntese do folhetinistacolibri:

O folhetinista é originário da França, onde nasceu, e onde vive a seu gosto [...]. De lá, espalhouse pelo mundo, ou, pelo menos, por onde maiores proporções tomava o veículo do espírito moderno; falo do jornal. [...]. O folhetinista, na sociedade, ocupa o lugar do colibri, na esfera vegetal: salta, esvoaça, brinca, tremula, paira e espaneja-se sobre todos os caules suculentos, sobre todas as seivas vigorosas. Todo mundo lhe pertence, até mesmo a política. (MACHADO DE ASSIS, 1997, p. 154; grifo nosso).

Machado celebra a ampla liberdade e a leveza da crônica. De tão concisa, sua definição agrega tudo (ou quase tudo) o que se tem dito sobre esse gênero volátil que, nas palavras de Drummond (em entrevista de despedida concedida ao "Jornal do Brasil"), "não obriga ao paletóe-gravata do editorialista [já que] não se exige do cronista a informação precisa que cobramos dos outros" (1984). A imagem machadiana do folhetinista-colibri, pousando sobre vários assuntos, é importante para se entender que o gatilho da crônica é o banal, o comezinho Não é à toa que Carlos Drummond intitula um de seus livros de crônicas De notícias \& não notícias faz-se a crônica - histórias, diálogos e divagações. O poeta e prosador não esconde sua predileção pelo jornal: "O meu cotidiano é um pouco maroto, sabe? [...]. Sou um leitor de jornal voraz. Sempre gostei muito de jornal. A única vocação que tive foi a de jornalista, e não a realizei plenamente" (DRUMMOND DE ANDRADE, 1980, p. 4), diz com modéstia. Voltado para a pauta desse universo, reconstitui, em "O poema do jornal" (Alguma poesia), a atmosfera da redação, traduzida "mecanicamente" por meio de versos sincopados, reproduzindo o toque-toque dos dedos na máquina de escrever. $\mathrm{O}$ que na poesia merece alguns versos pode virar matéria para uma reportagem ou uma crônica policial:

$\mathrm{O}$ fato ainda não acabou de acontecer

E já a mão nervosa do repórter a transforma em notícia

O marido está matando a mulher

A mulher ensanguentada grita

Ladrões arrombam o cofre

A polícia dissolve o meeting

A pena escreve

O que molda o cotidiano da crônica é a notícia e Machado habilmente percebe que a vida política cotidiana da Primeira República pode fornecer um bom manancial para seu vastíssimo repertório. Sem precisar 
fazer profissão de fé de neutralidade, pôde soltar, então, sua verve irônica, mantendo-se, na expressão de John Gledson "numa anonimidade muito curiosa":

Creio que abril, 1888, é uma data muito significativa na produção machadiana deste gênero. Acabara em fevereiro (sem anunciar o fato) a série rimada e jocosa da Gazeta de Holanda assinada Malvólio; a 5 de abril começa Bons dias!, assinada (não sei se é bom o termo) 'Boas noites'. Há uma diferença fundamental entre as duas séries: era fato público que Malvólio [...] era Machado [...] enquanto que Bons dias! foi mantida numa anonimidade muito curiosa.

Galante de Souza cita como prova da autoria uma lista manuscrita de pseudônimos que se encontra na Biblioteca Nacional. Sempre me pareceu um pouco inverossímil que um autor tão conhecido, e um cronista que, afinal de contas, era mestre do gênero, conseguisse a anonimidade [...]. (GLEDSON, 1997, p. 24).

Bem informado sobre os desvãos da sociedade brasileira, Machado espaneja-se sobre os "caules suculentos" do recente sistema político republicano. Um assunto comezinho, como por exemplo, o funcionamento da egrégia câmara dos deputados já é suficiente. É desse assunto que trata a crônica abaixo, assinada $\mathrm{A}+\mathrm{B}$ e publicada na Gazeta de Notícias, em 1886:

A - Estive há poucos minutos com uma senhora, que veio desconsolada da sessão da assembleia geral, vulgo fusão. Rejeitou um passeio nesse dia só para ter o gosto de ver a coisa, e não viu nada.

B - Como nada?

A Nada ou quase nada, disse-me ela. [...].

B - [...] Insinuei-lhe que era melhor que neste dia tivesse ido ela comigo à câmara dos deputados...

A - Mas não havia lá ninguém... (MACHADO DE ASSIS, 1956, p. 43)

Totalmente décousue, a crônica é composta de vaivéns. Resumidamente: fala-se da passagem de Vênus; da disposição e da quantidade de tribunas; do discurso do deputado Afonso Celso Júnior pedindo a supressão das bolas de votação, mesmo que as tais bolas coloridas não tivessem o nome do votante, pois "o sigilo [...] é alma deste mundo e do outro"; fala-se de chapéus, espécie de modelo exemplar para as reformas parlamentares e para as tribunas, já que, explicou a senhora, "o nosso chapéu vem todo da França, aos pedaços; aqui o que se faz, é enformálo, expô-lo, comprá-lo e usá-lo". A crônica apresenta os traços típicos da construção machadiana: discurso digressivo, comparações aparentemente disparatadas (tribunas $\times$ chapéus) deslizando facilmente para a ironia, recurso dominante amplamente estudado pela crítica. A ideia, comumente aceita, de que há uma continuidade orgânica entre o Machado folhetinista e o Machado ficcionista não é, como se vê, de forma alguma aleatória. Sonia Brayner alerta: "Foi o campo da crônica jornalística que forneceu a Machado de Assis o desembaraço preparatório para as experiências de um novo enunciado romanesco" (BRAYNER, 1978, p. 55). Continua Brayner: "O contato cotidiano como leitor historicamente datado, o trabalho sobre uma oralidade necessária ao gênero, vão dar-lhe elementos para pesquisar a tessitura literária" (loc.cit.). Porém, se há um traço permanentemente unindo as duas escritas, a cronística e a ficcional, esse é sem dúvida a sutil ironia machadiana. Pelo fato de a crônica proporcionar um comentário mais pessoal, mais solto, do objeto, é nela que Machado exerce livremente seu poder irônico, com a intenção de pôr à mostra as falhas do sistema republicano em seu processo nascente: políticos controlando cargos de mando; operações financeiras especulativas (o Encilhamento); ambições político-partidárias; ex-escravos excluídos da vida civil. Veja-se a crônica abaixo, da série Bons dias!, datada de 27 de maio, em que trata da queda de um meteorito na Bahia, fato que ocupou as páginas dos periódicos cariocas:

Cumpre não perder de vista o metereólito de Bendegó. Enquanto toda a nação bailava e cantava, delirante de prazer pela grande lei da abolição, o metereólito de Bendegó vinha andando, vagaroso, silencioso, científico ao lado do Carvalho.

- Carvalho, dizia ele provavelmente ao companheiro de jornada, que rumores são estes? Ao longe?

- E ouvindo a explicação, não retorquira nada, e pode ser até que sorrisse [...]. (MACHADO DE ASSIS, 1956, p. 90-91)

Mais uma vez Machado pega um evento qualquer (a queda de um meteorito em Bendegó), inventa uma situação (um diálogo imaginário entre o tal meteorito e o oficial da Armada, comandante José Carlos de Carvalho, que segundo nos informa Magalhães Júnior, organizador do volume, era chefe da expedição enviada ao interior da Bahia, a fim de recolher o aerólito caído há mais de um século às margens do riacho de Bendegó). para lançar suas farpas contra a mediocridade dos vereadores que "iam [se] reunir extraordinariamente, para saber se embargariam ou não a saída do meteorólito" (MACHADO DEASSIS, 1956, p. 91). Ao ouvir os rumores "ao longe" e as explicações sobre o motivo das danças em comemoração à abolição da escravidão, o meteorito (o "duplo" de Machado) silencia. Conforme afirma Valentim Facioli: "[Machado de Assis] denunciou a escravidão de muitas maneiras, mas especialmente procurou captar a organização ideológica que a mantinha. [...]. A denúncia nunca foi 
simplesmente panfletária, mas sempre integrada no conjunto das relações sociais [...] (FACIOLI, 1982, p. 49). Travestido de meteorito, Machado pode rir à socapa, zombar de nossas instâncias políticas e sociais. Somos, insinua, uns trapalhões. Não sabemos administrar nossos problemas. É interessante como na crônica machadiana não cabe a descrição individualizada de pessoas e de ambientes; cabe o fato em si, elemento que lhe permite ironizar criativamente o cotidiano da cidade. Liberdade criativa de que, aliás, também fez uso, a sua maneira, o turbulento João Paulo Emílio Cristovão dos Santos Barreto (João do Rio, 1881-1921) ${ }^{1}$, que, conforme se verá, procurou dar outra dimensão ao gênero.

\section{João do Rio e a pressa de acabar}

Antigamente as horas eram entidades que os homens conheciam imperfeitamente. [...] Inventavamse relógios de todos os moldes e formas. [....]. Hoje nós somos escravos das horas [...]. 'Dar tempo ao tempo' é uma frase feita cujo sentido a sociedade perdeu integralmente. Já nada se faz com o tempo. Agora faz-se tudo por falta de tempo. (RIO, 1909, p. 384)

Na crônica acima, intitulada "A pressa de acabar", o autor de Cinematógrafo - crônicas cariocas contrapõe o tempo medieval, regulado pelas estações do ano tempo duradouro, tempo cósmico, tempo místico - ao tempo moderno, regulado pelas horas, "[essas] senhoras inexoráveis que não cedem nunca e cortam o dia da gente numa triste migalharia de segundos" (ibid., 385). Elegendo a velocidade como algo inerente ao homo cinematographicus $^{2}$, João do Rio desenvolve suas crônicas - e toda sua obra - sob a égide do imediato. Gilberto Amado sintetiza o impacto:

Num tempo em que fúria normativa disciplinava os gêneros, e seus representantes mais ranzinzas mediam o valor do verso pelo critério discutível de riqueza/pobreza ou o valor do romance pelo apego documental, um carioca atrevido, como João do Rio, embaralhava propositadamente as cartas, ignorava as regras do bom comportamento jornalístico, embarafustava por locas comprometedoras a fim de proteger do esquecimento os hábitos de tatuagem, a festa do Natal entre os remanescentes da escravaria e as atitudes viciadas dos candidatos eleitos. (AMADO, 1956, p. 63 - grifo nosso)

\footnotetext{
Não se pretende discorrer, aqui, sobre a versatilidade da crônica de João do Rio. Ver, a esse respeito, os títulos contidos nas referências.

2 Caso haja interesse, o leitor poderá consultar nosso artigo intitulado "João do Rio: o homus cinematographicus", publicado na revista intitulada Rio de Janeiro - a literatura no Rio de Janeiro. n. 20-21, jan. dez. 2007. Universidade do Estado do Rio de Janeiro (UERJ), p. 191-202. ISSN 0102-8863.
}

Contemporâneo e amigo de João do Rio, Amado percebe que a inventividade do autor de $A$ alma encantadora das ruas reside em mostrar o lado obscuro da cidade, ignorado pelas camadas mais altas do país. De fato, em crônicas de recorte antropológico e social, João do Rio observa in loco os artistas que trabalham na informalidade ("A pintura das ruas"), conversa com os meninos de rua ("Crianças que matam"), prostitutas e pedintes ("Mulheres mendigas"). Em As religiões no Rio, frequenta os ritos religiosos, ligados ao culto da possessão, desmentindo dessa forma o mito da supremacia do catolicismo. Porém, para quem julga que o cronista carioca sempre tece loas ao progresso, a crônica "O velho mercado" mostra um narrador descrente do fenômeno da urbanização (conhecido, popularmente, como "o bota abaixo"). Em meio ao bulício urbano, e ao ritmo das demolições que ameaçavam destruir a cidade colonial, João do Rio descreve uma velha praça, a praça do Mercado. Aqui, o processo de urbanização (19031904), realizado pelo prefeito Francisco Pereira Passos (1863-1913) durante o governo de Rodrigues Alves (1902-1906), fotografado pelo alagoano Augusto Malta (1860-1957) é um poço de incoerências:

Acabou de mudar-se ontem a praça do Mercado. Naquele abafado e sombrio dia de ontem era um correr de carregadores e carrinhos de mão pelos squares rentes ao Faroux levando as mercadorias da velha praça abandonada para a nova instalação catita do largo do Moura [...]. A mudança! Nada mais inquietante do que a mudança - porque leva a gente amarrada (sic) essa esperança, essa tortura vaga que é a saudade. Aquela mudança era, entretanto, maior do que todas, era uma operação de cirurgia urbana, era para modificar inteiramente o Rio de outrora, a mobilização do próprio estômago da cidade para outro local. Que nos resta mais do velho Rio antigo, tão curioso e tão característico? Uma cidade moderna é como todas as cidades modernas [...]. O Rio, cidade nova - a única talvez no mundo - cheia de tradições, foi-se delas despojando com indiferença. (RIO, 1909, p. 213-214-215 - grifo nosso)

Para João do Rio, "a cidade maravilhosa" - aposto famoso, atribuído a Jeanne Catulle Mendès, durante sua visita ao Rio - estava perdendo sua singularidade. Constatação sumarizada na pergunta: "Que nos resta mais do velho Rio antigo?". "Toda cotidianidade é histórica", diz Kosik (1976, p. 72), pois "só na teoria materialista todo processo humano é histórico, com o que se supera o dualismo entre a cotidianidade não-histórica e a historicidade da História" (ibid., loc. cit.). João do Rio procurou superar esse dualismo anti-histórico, ouvindo prostitutas, operários, ambulantes, mendigos e mendigas, meninos de rua, pessoas iletradas, incapazes de escrever 
seus relatos, como o fizeram representantes das camadas abastadas. Suas descrições, pormenorizadas e sem qualquer afetação - uma maneira, sem dúvida, de manter uma conexão com o real - lembram, em certa medida, os já citados viajantes, Koster e Coudreau. O diálogo abaixo, curto e meticuloso - quase um condutor narrativo - serve naturalmente para agilizar a narração do fato, sem quaisquer intuitos retóricos. A impressão de veracidade fica por conta do leitor da época:

Humildes! Quanta cousa se vê e se ouve (que é impossível contar) de miséria, de sentimento, de irreparável, de infinita candura nessas pobres almas sem luz. [...]. Das pequenas cenas, duas voltamse à memória continuamente. [...]. Na primeira, um rapazola, carroceiro, caíra da boleia fraturando a perna. [...].

Interrompi a autoridade [...].

- Há quanto tempo você é carroceiro?

- Há muito... desde criança... há dez anos para a mãe que é viúva.(Ibid., p. 196)

$\mathrm{Na}$ base das grandes fortunas está o trabalho do operário, vivendo um cotidiano de privações de longas jornadas e parcos salários, é o que denuncia o cronista em "A trilogia da miséria", formada pelas crônicas "Os humildes" (acima citada), "A fome negra"; "Trabalhadores da estiva", crônicas em que, na percepção arguta de Candido (1980), o jornalista-cronista termina sendo o denunciador das contradições da estrutura social de seu tempo. Esse cotidiano doloroso forma um contraste chocante com este outro, permeado de frivolidades. A mesma cidade dos miseráveis é também a cidade de gostos e rituais aristocráticos. Aqui, a voz narrativa é irônica e sarcástica:

A estação de inverno está oficialmente aberta. Esta frase, de cuja elegância social ninguém duvida, significa com amplidão que a cidade, farta de descansar das violências caniculares, resolve entregarse doidivanas e perdulária, ao oceano do agitado prazer. O prazer é estar em toda parte onde a gente se diverte ou finge divertir [se]: nas regatas, nos prados, nos campos de foot-ball, nos restaurants chics, nas recepções de etiquetas, nos teatros, na (sic) aluvião de companhias estrangeiras que nos chegam por todos os vapores. (Ibid., p. 55)

A despeito da infinidade de assuntos que caracterizam a cotidianidade, será possível extrair dessas narrativas de circunstâncias, destinadas, como bem assinalou Candido (1992, 14), a "embrulhar [no dia seguinte] um par de sapatos ou forrar o chão da cozinha", um sentido geral que trairia sua dispersão? Em outras palavras, é possível extrair desses relatos esparsos uma unidade de pensamento? Deslocando-se de um lugar para outro, em uma agitação febril, João do Rio, sem dúvida, temeu essa dispersão e, precavido, tratou de reunir boa parte de suas crônicas - que somam um total de 2.362, assegura-nos João Carlos Rodrigues (1994) - em volume (a primeira edição do Cinematógrafo apresenta capa marrom e título em letras góticas douradas) num desejo incontido, não só de dar um caráter perene a uma escrita volátil mas de revelar as faces de uma cidade contraditória, em que se mesclam a mais extrema pobreza e elementos de uma falsa modernidade. No essencial, sua crônica não toma a forma de um gênero híbrido, a meio caminho entre invenção e jornalismo, nem ganha experiência biográfica no sentido estrito do termo. Sua crônica é autêntica no sentido histórico e jornalístico. E ele sabia disso:

A minha obra só poderá ser vista, em conjunto, dentro de dez anos. Aí verão, talvez, que eu tentei ser o reflexo tumultuário de transformações e que nos meus livros não está a obra prima, mas em todos os seus aspectos morais, políticos, sociais, mundanos, ideológicos, práticos - a vida do Rio. (Apud BEZERRA DE FREITAS, s.d., p. 20)

A obra de João do Rio aguardou, conforme previra Luiz Edmundo (1956, p. 567), "o trabalho lento e paciente das horas". O que, de certo modo, não deixa de ser quase um insulto para um homem que, nas palavras de Freitas (s.d., 11) "sofria a tortura do movimento" e vivia sofregamente seu tempo:

Eu não tenho tempo! Tenho notas, observações, esquemas para 40 ou 50 volumes, e com 36 anos e a dura luta pela vida, é totalmente impossível realizálos. Há enredos de livros que resumo em crônicas e contos [...]. Creia-me, a minha dor vem, não da impossibilidade de os escrever, mas de não serem eles escritos, já. (RODRIGUES, 1996, p. 220)

Não se espere da crônica, disseram Machado e Drummond, uma análise aprofundada das relações humanas e das configurações sociais, pois, o que assegura a comunicação entre o cronista-folhetinista e o leitor de jornal é a leveza da linguagem, aliada a uma percepção afinada do objeto, pois "invadindo ora o terreno do comentário ou do artigo, ora o do conto ou do poema, o cronista parece não ter outra obrigação senão esta de, dentro de um espaço reduzido e em tom displicente interessar o leitor ou, em outras palavras, ter talento. (RÓNAI, 1958, p. 180). Mas, o que mudou na crônica nas seis décadas que separam Machado e João do Rio de um cronista como Drummond? Pelo tudo que já foi dito e a crer, agora, em Carpeaux, praticamente nada, a não ser, evidentemente, as perspectivas discursivas assumidas e uma certa visão de mundo. A imagem machadiana do 
folhetinista-colibri permanece na pena de Drummond, revelando aquele ar de cotidianidade inerente ao gênero.

Fala, amendoeira [de Drummond] é um livro sobre assuntos de toda espécie: sobre mentiras, lugares, costumes, problemas, datas, letras, bichos, meninos, situações e despedidas. Ao cronista nada é alheio que é humano e infra-humano; da falta d'água em cima até a situação política em baixo. Muita coisa que vemos diariamente sem percebê-la desperta-lhe a atenção. [...] (CARPEAUX, 1999, p. 867).

A cotidianidade está na essência da crônica. Aí reside seu fascínio. Talvez por isso o gênero guarde, até hoje, uma perenidade entre nós.

\section{Referências}

ARRUGUCI JR., Davi. Enigma e comentário: ensaios sobre literatura e experiência. São Paulo: Companhia das Letras, 1987.

AMADO, Gilberto. João do Rio. In: Mocidade no Rio e primeira viagem à Europa. Rio de Janeiro: José Olympio, 1956.

BRASIL, Antonio. Álvaro Lins e Henry Koster. In: Revista do Arquivo Público, Recife: v. 30, n. 32, dez. 1976.

BENJAMIN, Walter. Magia, técnica, arte e política - ensaios sobre a literatura e história da cultura. 5. ed. Tradução de Sérgio Paulo Rouanet. São Paulo: Brasiliense, 1993.

BRAYNER, Sonia. As metamorfoses machadianas. In: Labirinto do espaço romanesco. Rio de Janeiro: Civilização Brasileira; Brasília: INL, 1979.

CANDIDO, Antônio. A vida ao rés do chão. In: et alli. A crônica: o gênero, sua fixação e suas transformações no Brasil. Campinas, SP: Editora da UNICAMP; Rio de Janeiro: Fundação Casa de Rui Barbosa, 1992.

CANDIDO, Antônio. Radicais de ocasião. In: Teresina etc. Rio de Janeiro: Paz e Terra, 1980.

CARPEAUX, Otto Maria. O poeta e as moscas. In: Obras reunidas - 1942-1978. v. 1. Rio de Janeiro: UniverCidade/ Topboks, 1999.

CHAMIE, Mário. A prosa peregrina da carta de Caminha. In: . A palavra inscrita. Rio de Janeiro: FUNPEC, 2004.

COUDREAU, Henri. Viagem a Itaboca e ao Itacaiúnas. Tradução de Eugênio Amado. São Paulo: Editora da Universidade de São Paulo, 1980.

CRÔNICA DO CONDESTÁVEL DE PORTUGAL D. NUNO ÁLVARES PEREIRA. 3. ed. Lisboa: Tipografia Minerva, 1953. [Adaptação por Jaime Cortesão. Ilustrações de Martius Barata].
DRUMMOND DE ANDRADE, Carlos. Ciao. In: Jornal do Brasil, Rio de Janeiro, 29 de setembro de 1984. Caderno B.

DRUMMOND DE ANDRADE, Carlos. Eu fui um homem qualquer. [Entrevista concedida a Zuenir Ventura]. In: Revista Veja, 19 de novembro, 1980.

EDMUNDO, Luiz. João do Rio. In: De um livro de memórias. Rio de Janeiro: Departamento de Imprensa Nacional, 1956.

ETTE, Ottmar. Os caminhos do desejo. Coreografias de viagens: um ensaio sobre sua multidimensionalidade e as figuras fundamentais dos movimentos que coloca em cena. In: Revista Humboldt, Goethe Institut, n. 89, 2004.

FACIOLI, Valentim. Várias histórias para um homem célebre (biografia intelectual). In: GARBUGLIO, José Carlos et alli. Machado de Assis. São Paulo: Ática, 1982.

FREITAS, Bezerra de. Prefácio ao conto "O bebê de tarlatana rosa". Rio de Janeiro: Brasileira Lux, s. d.

GLEDSON, John. A política na crônica de Machado de Assis. In: Gêneros de fronteiras entre a história e o literário. São Paulo: Xamã, 1997.

GOULEMOT, Jean-Marie. Sur les traces des écrivains voyageurs. In: Magazine littéraire, n. 432, juin 2004.

KOSIK, Karel. Metafísica da vida cotidiana. In: Dialética do concreto. 2. ed. Tradução Célia Neves e Alderico Toríbio. Rio de Janeiro: Paz e Terra, 1976.

KOSTER, Henry. Viagens ao Nordeste do Brasil. Tradução de Luís da Câmara Cascudo. 2. ed. Recife: Secretaria de Educação e Cultura, 1978.

LEFEBVRE, H. Introducción a la psicosociologia de la vida cotidiana. In: La vida cotidiana en el mundo moderno. Madri: Editorial S/A, 1972.

MACHADO DE ASSIS, José Maria. Balas de estalo \& crítica - crônicas. São Paulo: Globo, 1997.

MACHADO DE ASSIS, José Maria. Diálogos e reflexões de um relojoeiro. Rio de Janeiro: Civilização Brasileira, 1956.

RODRIGUES, João Carlos. Catálogo bibliográfico. Rio de Janeiro: Prefeitura da Cidade do Rio de Janeiro Secretaria Municipal de Cultura, 1994.

RODRIGUES, João Carlos. João do Rio - uma biografia. Rio de Janeiro: Topbooks, 1996.

RÓNAI Paulo. Divagações sobre a crônica em geral e uma cronista em particular. In: Encontros com o Brasil. Rio de Janeiro: Ministério de Educação e Cultura, 1958.

Recebido: 28 de agosto 2014

Aprovado: 10 de outubro 2014 Contato: gildabrandao@gmail.com 